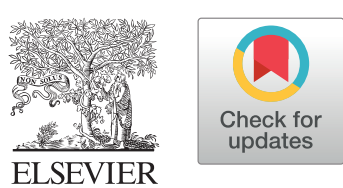

\title{
Review
}

\section{Cardiovascular Collapse in COVID-19 Infection: The Role of Venoarterial Extracorporeal Membrane Oxygenation (VA-ECMO)}

\author{
Justin Chow, MD, FRCPC, ${ }^{a}$ Anhar Alhussaini, MBBS, FRCPC, ${ }^{\text {b,c }}$ Oscar Calvillo-Argüelles, MD,, d \\ Filio Billia, MD, PhD, FRCPC, ${ }^{\text {b,de }}$ and Adriana Luk, MD, MSc, FRCPC ${ }^{\text {b,d }}$ \\ ${ }^{a}$ Division of Cardiology, Department of Medicine, McMaster University, Hamilton, Ontario, Canada \\ ${ }^{b}$ Division of Cardiology, Department of Medicine, University of Toronto, Toronto, Ontario, Canada \\ ${ }^{c}$ College of Medicine, King Saud bin Abdulaziz University for Health Sciences, Jeddah, Saudi Arabia \\ ${ }^{d}$ Peter Munk Cardiac Centre, Ted Rogers Center for Heart Research, University Health Network, Toronto, Ontario, Canada \\ ${ }^{e}$ Medical Director, Mechanical Circulatory Support Program, Peter Munk Cardiac Centre, University Health Network, Toronto, Ontario, Canada
}

\begin{abstract}
Coronavirus Disease 2019 (COVID-19) has been associated with cardiovascular complications, including acute cardiac injury, heart failure, and cardiogenic shock (CS). The role of venoarterial extracorporeal membrane oxygenation (VA-ECMO) in the event of COVID-19-associated cardiovascular collapse has not been established. We reviewed the existing literature surrounding the role of VA-ECMO in the treatment of coronavirus-related cardiovascular collapse. COVID-19 is associated with a higher incidence of cardiovascular complications compared with previous coronavirus outbreaks (Severe Acute Respiratory Syndrome Coronavirus and Middle East Respiratory Syndrome Coronavirus). We found only 1 case report from China in which COVID19-associated fulminant myocarditis and CS were successfully rescued using VA-ECMO as a bridge to recovery. We identified potential clinical scenarios (cardiac injury, myocardial infarction with and
\end{abstract}

The unprecedented global spread of the Coronavirus Disease 2019 (COVID-19) pandemic has resulted in the escalating impact on morbidity and mortality across the world, as well as substantial policy change and strain on existing healthcare infrastructure. Although these figures have not been firmly established, a recently published systematic review and metaanalysis of 19 observational studies of 2874 patients with confirmed COVID-19 infection showed a pooled prevalence

Received for publication March 28, 2020. Accepted April 4, 2020.

Ethics Statement: The research reported has adhered to the relevant ethical guidelines.

Corresponding author: Dr Adriana Luk, Toronto General Hopsital, 585 University Avenue, Toronto ON M5G 1V7. Tel.: 416-340-4800; fax: 416340-4134.

E-mail: adriana.luk@uhn.ca

See page 277 for disclosure information.

\section{RÉSUMÉ}

La maladie à coronavirus 2019 (COVID-19) est associée à des complications cardiovasculaires, y compris des lésions cardiaques aiguës, l'insuffisance cardiaque et le choc cardiogénique (CC). Le rôle de l'oxygénation par membrane extracorporelle (ECMO pour extracorporeal membrane oxygenation) veino-artérielle dans les cas de collapsus cardiovasculaire associé à la COVID-19 n'a pas été établi. Nous avons passé en revue la documentation existante abordant le rôle de l'ECMO veino-artérielle dans le traitement du collapsus cardiovasculaire lié au coronavirus. La COVID-19 est associée à une incidence plus élevée de complications cardiovasculaires comparativement aux éclosions antérieures d'infections à coronavirus (syndrome respiratoire aigu sévère et syndrome respiratoire du MoyenOrient). Nous n'avons trouvé qu'un seul cas (signalé en Chine) de myocardite fulminante et de CC associés à la COVID-19 où l'ECMO of intensive care unit admission of $20.3 \%$, shock (unspecified) in $6.2 \%$, and a case fatality rate of $13.9 \%$ for infected patients. ${ }^{1}$ Amidst our present struggles to contain the spread of infection and develop a vaccine, researchers have yet to identify beneficial treatments and therapies in managing patients with COVID-19 infection.

The COVID-19 pandemic has also uncovered salient issues in bioethics, including stewardship of scarce resources and provision of care to those most likely to benefit. Such dilemmas have already been faced by physicians in Italy who have described "warlike" situations in hospitals. ${ }^{2,3}$ Extracorporeal membrane oxygenation (ECMO) is a resource-intensive form of both respiratory and mechanical circulatory support in the setting of refractory respiratory failure and cardiogenic shock (CS), respectively. ${ }^{4}$ ECMO requires specialized equipment, training (of physicians, nursing staff, and perfusionists), and delivery of care in specialized critical care units. Despite the 
without obstructive coronary artery disease, viral myocarditis, and decompensated heart failure) leading to CS and risk factors for poor/ uncertain benefit (age, sepsis, mixed/predominantly vasodilatory shock, prothrombotic state or coagulopathy, severe acute respiratory distress syndrome, multiorgan failure, or high-risk prognostic scores) specific to using VA-ECMO as a bridge to recovery in COVID-19 infection. Additional considerations and proposed recommendations specific to the COVID-19 pandemic were formulated with guidance from published data and expert consensus. A small subset of patients with cardiovascular complications from COVID-19 infection may progress to refractory CS. While accepting that resource scarcity may be the overwhelming concern for healthcare systems during this pandemic, VA-ECMO can be considered in highly selected cases of refractory CS and echocardiographic evidence of biventricular failure. The decision to initiate this therapy should take into consideration the availability of resources, perceived benefit, and risks of transmitting disease.

poor survival of patients referred for venovenous (VV)-ECMO, interim recommendations from the Chinese, ${ }^{5,6}$ World Health Organization, ${ }^{7}$ and Surviving Sepsis Campaign ${ }^{8}$ suggest referral for VV-ECMO in cases of COVID-19 pneumonia and refractory hypoxemia despite conventional therapies. ${ }^{9,10}$

As COVID-19 has been associated with a multitude of cardiovascular complications, ${ }^{11-13}$ the role of venoarterial (VA) ECMO in the event of COVID-19-associated cardiovascular collapse has not been established. We sought to review the existing evidence surrounding the role of VA-ECMO in the treatment of coronavirus-related cardiovascular collapse in an effort to provide some guidance to providers in the face of the COVID-19 pandemic.

\section{Cardiovascular Compromise in COVID-19 Infection}

Compared with other major coronavirus outbreaks such as Severe Acute Respiratory Syndrome and the Middle East Respiratory Syndrome, COVID-19 has been associated with an increased incidence of cardiovascular complications. ${ }^{11}$ In one large cohort study of 138 patients, a significant proportion of patients presented with shock (unspecified; 8.7\%), acute cardiac injury (7.2\%), and arrhythmias (16.7\%), and 4 of 138 patients received unspecified ECMO support. ${ }^{14}$ Various case series have also reported new-onset heart failure/cardiomyopathy as a complication in up to one-third of critically ill patients admitted with COVID-19 infection. ${ }^{9,15}$ ST-segment elevation in COVID-19-associated myopericarditis has also led to false activations of the cardiac catheterization laboratory. ${ }^{16}$ Furthermore, among hospitalized patients, the presence of cardiac injury (defined as cardiac troponin $>99$ th percentile upper reference limit) has been independently associated with a 4-fold increased risk of mortality in patients infected with COVID-19, ${ }^{17}$ with even veino-artérielle a permis d'assurer la survie du patient dans l'attente d'une récupération de la fonction cardiaque. Nous avons ciblé divers scénarios cliniques (lésion cardiaque, infarctus du myocarde avec ou sans coronaropathie obstructive, myocardite virale et insuffisance cardiaque décompensée) susceptibles d'aboutir à un $\mathrm{CC}$ et cerné des facteurs de risque de bienfaits faibles ou incertains (âge, septicémie, choc vasodilatateur mixte ou prédominant, état prothrombotique ou coagulopathie, syndrome de détresse respiratoire aiguë sévère, défaillance multiviscérale ou scores pronostiques à haut risque) cadrant spécifiquement avec l'utilisation de I'ECMO veino-artérielle dans l'attente d'une récupération de la fonction cardiaque chez le patient atteint de COVID-19. D'autres considérations et recommandations visant spécifiquement la pandémie de COVID-19 ont été énoncées à la lumière des données publiées et d'un consensus d'experts. Au sein d'un petit sous-groupe de patients atteints de COVID-19, les complications cardiovasculaires de l'infection peuvent évoluer vers un $\mathrm{CC}$ réfractaire. Tout en acceptant que la pénurie de ressources puisse être la principale préoccupation des systèmes de santé pendant cette pandémie, on peut envisager de recourir à l'ECMO veino-artérielle dans des cas soigneusement sélectionnés de $\mathrm{CC}$ réfractaire et en présence de preuves échocardiographiques d'insuffisance biventriculaire. La décision d'instaurer ce traitement doit tenir compte de la disponibilité des ressources, des avantages perçus et des risques de transmission de la maladie.

poorer prognosis in patients who have underlying cardiovascular disease. ${ }^{18}$ The mechanisms by which COVID-19 affects the cardiovascular system remain poorly understood, but postulated mechanisms include direct myocardial injury, indirect injury through cytokine release, a prothrombotic state causing microvascular thrombosis, and exacerbation of underlying cardiovascular disease, for example, plaque rupture in susceptible patients. ${ }^{11-13}$

We identified 2 cases from China in which COVID-19associated fulminant myocarditis and CS were successfully treated. ${ }^{19,20}$ In both cases, the diagnosis of COVID-19 was confirmed by sputum nucleic acid testing. Both patients had markedly elevated cardiac biomarkers (troponin I/T, N-terminal pro-B-type natriuretic peptide) and depressed left ventricular ejection fraction by transthoracic echocardiography, and were treated with empiric broad-spectrum antimicrobials, intravenous immunoglobulin, and corticosteroids. In one of these patients, mechanical circulatory support in the form of VA-ECMO was used as a bridge to recovery (BTR) with successful hemodynamic and biochemical improvement. ${ }^{20}$ Moreover, myopericarditis with left ventricular dysfunction requiring inotropic support has been reported in the absence of significant pulmonary manifestations. ${ }^{16}$

\section{VA-ECMO and COVID-19}

The Extracorporeal Life Support Organization (ELSO) recommends consideration of VA-ECMO in refractory CS that persists despite adequate fluid resuscitation, inotropes, and vasopressor support. ${ }^{21}$ Contraindications to VA-ECMO include (but are not limited to) advanced age, lifethreatening noncompliance, and significant medical comorbidities (eg, severe emphysema or cirrhosis). ${ }^{21}$ To our knowledge, there are no reported case series related to the use 
of VA-ECMO in prior coronavirus outbreaks, including Severe Acute Respiratory Syndrome and Middle East Respiratory Syndrome. Accordingly, we anticipate that patient selection for VA-ECMO in the setting of COVID-19 infection will be a challenging task. However, identification of potential clinical scenarios leading to CS and circumstances unique to COVID-19 may facilitate decision-making (Table 1), ideally by a multidisciplinary CS team that includes representation of cardiac surgery, cardiology, intensive care, anesthesia, and advanced heart failure/transplant physicians.

Unique clinical features of COVID-19 need to be recognized before considering candidacy for VA-ECMO cannulation in patients with circulatory collapse (Table 2). Age is an independent predictor of mortality among patients receiving VA-ECMO,${ }^{4}$ and in a multivariable analysis of patients with COVID-19 by Zhou et al., ${ }^{9}$ it was associated with approximately $10 \%$ increased risk of death per year. It is of utmost importance to document the presence of both biventricular dysfunction and a hemodynamic profile compatible with CS, because patients with mixed or predominantly vasodilatory shock may be unlikely to benefit from mechanical circulatory support even in the presence of known cardiovascular disease. Although patients with COVID-19 infection are in a proinflammatory and prothrombotic state, coagulopathy has been reported in up to one-fifth of cases. 'Thus, vigilant monitoring for both thrombotic complications (intracardiac thrombi, aortic root/aortic valve thrombi, cannula thrombi, thrombosis of oxygenator) and bleeding may be warranted. Last, severe cases of COVID-19 tend to present with multiorgan failure. The use of VA-ECMO in such patients, especially in the presence of severe acute respiratory distress syndrome complicated by sepsis, may be considered a futile

Table 1. Disease-specific clinical scenarios that may lead to CS in COVID-19 infection

\begin{tabular}{|c|c|}
\hline Clinical scenario & Comments \\
\hline Cardiac injury & $\begin{array}{l}\text { Cardiac injury is defined by troponin } \\
\text { elevation and can encompass direct } \\
\text { myocardial insult or indirect injury } \\
\text { due to sepsis, hypoxia, or cytokine } \\
\text { release. Left ventricular dysfunction } \\
\text { and ventricular arrhythmias may be } \\
\text { present. }\end{array}$ \\
\hline $\begin{array}{l}\text { Myocardial infarction in the } \\
\text { absence of Obstructive } \\
\text { coronary artery disease }\end{array}$ & $\begin{array}{l}\text { May result from supply/demand } \\
\text { mismatch (Type } 2 \text { MI) or } \\
\text { microvascular thrombosis }\end{array}$ \\
\hline Viral myocarditis & $\begin{array}{l}\text { Fulminant myocarditis can lead to } \\
\text { rapidly progressive CS. }\end{array}$ \\
\hline Acute myocardial Infarction & $\begin{array}{l}\text { Plaque rupture resulting in STEMI/ } \\
\text { NSTEMI can be exacerbated as the } \\
\text { result of underlying prothrombotic/ } \\
\text { proinflammatory state. }\end{array}$ \\
\hline $\begin{array}{l}\text { Acute Decompensated Heart } \\
\text { Failure }\end{array}$ & $\begin{array}{l}\text { Can result from decompensation in } \\
\text { patients with known or subclinical } \\
\text { cardiomyopathy or from a new } \\
\text { process (eg, Takotsubo/stress } \\
\text { cardiomyopathy, septic } \\
\text { cardiomyopathy, right ventricular } \\
\text { dysfunction) }\end{array}$ \\
\hline
\end{tabular}

CS, cardiogenic shock; MI, myocardial infarction; NSTEMI, non-ST-segment elevation myocardial infarction; STEMI, ST-segment elevation myocardial infarction.
Table 2. Risk factors for poor/uncertain benefit from VA-ECMO as BTR in COVID-19 infection

Risk factor

Older age

Sepsis

Mixed or predominantly vasodilatory shock

Prothrombotic state or coagulopathy

Concomitant severe ARDS

Multiorgan failure

High-risk prognostic score (SOFA, SAVE)

ARDS, acute respiratory distress syndrome; BTR, bridge to recovery; SAVE, Survival after Veno-arterial ECMO; SOFA, Sequential Organ Failure Assessment; VA-ECMO, venoarterial extracorporeal membrane oxygenation.

resource-intensive endeavor. Use of validated prognostic scores such as the Sequential Organ Failure Assessment and Survival after Veno-arterial ECMO scores together with clinical judgment should be encouraged to identify those who are more likely to have an exit strategy, such as BTR. ${ }^{22}$ The use of VA-ECMO during cardiac arrest is beyond the scope of this review. However, reported poor outcomes need to be considered before endeavoring to use this approach. We identified 1 case in which a 79-year-old female patient with COVID-19 infection was emergently cannulated for VAECMO during cardiac arrest and cardiopulmonary resuscitation, but unfortunately this patient died shortly afterward. ${ }^{6}$

By using correspondence from existing societal bodies $^{7,23,24}$ and lessons from the experience in China, ${ }^{5,6}$ we have distilled the major considerations and recommendations for VA-ECMO specific to COVID-19 in Table 3. As international experts have written extensively on the major infrastructure changes needed to support patients with COVID-19 with VV-ECMO during this pandemic, ${ }^{25,26}$ we expect that much of this will also apply to patients being considered for VA-ECMO in the setting of refractory CS.

The ethical circumstances surrounding allocation of scarce resources during a pandemic tend to favor a utilitarian approach to maximize collective benefit. Important ethical considerations are outlined in the recently published article by Emanuel et al., ${ }^{27}$ with additional recommendations to prioritize certain groups when constrained by limited resources: healthcare workers, sickest first, and youngest first. ELSO has published guidance ${ }^{23}$ surrounding use of ECMO during this pandemic that align with these principles, namely, that the highest priority should be given to younger patients, those with minor/no medical comorbidities, and healthcare workers. Outside of this, standard ECMO inclusion/exclusion criteria and COVID-19 protective equipment should be used according to local institutional policies, because there are currently no special precautions recommended for contact. ${ }^{23}$ Although there is a theoretical risk of microbial aerosolization in the membrane oxygenator, this has not been substantiated by evidence, ${ }^{28}$ and we do not recommend any special precautions other than vigilant decontamination and disposal of equipment as governed by local institution and infection-control policies.

Pertaining to the provision of ECMO, this is dependent on local institution and regional policies, and providing this level of care should be considered dynamically on a case-by-case basis as the local situation and resource availability changes (ie, critical care beds, healthcare personnel, equipment). In peripheral centers where ECMO is not readily available, 
Table 3. Additional considerations and proposed recommendations for VA-ECMO during the COVID-19 pandemic

\begin{tabular}{|c|c|}
\hline Category & Recommendations \\
\hline $\begin{array}{l}\text { Ethical considerations for resource } \\
\text { allocation }\end{array}$ & $\begin{array}{l}\text { ECMO should be provided only if institutional resource constraints allow for it. } \\
\text { The following groups should be given priority: } \\
\text { Sickest first } \\
\text { レ Youngest first } \\
\text { Greatest perceived benefit } \\
\text { レ Fewest/no comorbidities } \\
\text { Healthcare workers }\end{array}$ \\
\hline $\begin{array}{l}\text { Patient selection, timing, and } \\
\text { management }\end{array}$ & $\begin{array}{l}\text { Determined by standard societal (ELSO, CCS, WHO) and institutional protocols } \\
\text { At present, this includes: } \\
\\
\text { Case-by-case discussion with interdisciplinary heart team } \\
\text { Usual patient selection criteria as for patients without COVID-19 } \\
\text { Standard administration, monitoring (eg, POCUS, hematologic parameters) and management of complications } \\
\text { Patients referred for consideration of VA-ECMO from peripheral centres should be discussed } \\
\text { on a case-by-case basis (including the decision to transfer to a specialized center vs cannulate } \\
\text { on-site). }\end{array}$ \\
\hline $\begin{array}{l}\text { Environmental and infection control } \\
\text { precautions }\end{array}$ & $\begin{array}{l}\text { Determined by standard institutional protocols: } \\
\text { At present, this includes: } \\
\\
\text { Patients on ECMO should be in negative pressure isolation rooms when possible } \\
\text { N } 95 \text { masks for aerosol-generating medical procedures only } \\
\text { Droplet-contact precautions otherwise including during cannulation and routine rounding }\end{array}$ \\
\hline Handling of ECMO equipment & $\begin{array}{l}\text { All ECMO equipment should be used and disposed of according to local institutional and infection control policies } \\
\text { with attention to practicing strict decontamination. }\end{array}$ \\
\hline VA-ECMO during E-CPR & $\begin{array}{l}\text { E-CPR should be performed only at experienced institutions (depending on local policy, perceived risk-to-benefit } \\
\text { ratio, and availability of resources) because the uncontrolled environment of cardiac arrest can pose significant risk } \\
\text { of cross-contamination and transmitting infection. }\end{array}$ \\
\hline
\end{tabular}

CCS, Canadian Cardiovascular Society; CRRT, continuous renal replacement therapy; ECMO, extracorporeal membrane oxygenation; E-CPR, extracorporeal membrane oxygenation during cardiopulmonary resuscitation; ELSO, Extracorporeal Life Support Organization; POCUS, point-of-care ultrasound; VA-ECMO, venoarterial ECMO; WHO, World Health Organization.

additional considerations, such as ensuring fair resource allocation and deciding to transfer to a specialized center vs cannulation on-site, should be determined by similar principles.

At our centre (University Health Network, Toronto), ECMO is considered on a case-by-case basis using an interdisciplinary heart team approach in accordance with the most up-to-date ELSO and Canadian Cardiovascular Society recommendations. To date, we have not had any cases of COVID-19 that have required consideration for VV-ECMO or VA-ECMO. That said, this is an evolving situation that may change as more affected patients are expected to require critical care beds in the coming weeks to months. In our current circumstances worldwide, as MacLaren et al. ${ }^{26}$ suggest, resources may well be better concentrated to ensure that enough intensive care unit beds, ventilators, and personal protective equipment are available to deal with the influx of patients encountered within the coming weeks to months. As the authors aptly assert, "ECMO is not a therapy to be rushed to the frontline when all resources are stretched in a pandemic." ${ }^{26}$

\section{Conclusions}

COVID-19 has the potential to cause significant cardiovascular compromise warranting consideration for advanced therapies in a small subset of affected patients. Frontline providers of all specialties must stay up-to-date with the ever-evolving literature and be familiar with therapeutic options for COVID-19 infections. VV-ECMO and VA-ECMO remain resource-intensive forms of respiratory and mechanical circulatory support that can be considered in extreme circumstances. In the present time of global uncertainty with limited evidence to guide care, we must be mindful of balancing resource scarcity (which may be the overwhelming concern for many healthcare systems in the course of this pandemic) with perceived likelihood of benefit, as well as the risk of transmission to other patients, healthcare providers, and patient-care environments. We anticipate that Extracorporeal Membrane Oxygenation for 2019 Novel Coronavirus Acute Respiratory Disease (ECMO-CARD), an ongoing multicenter prospective observational study of ECMO use in COVID-19, will inform practice for both VV-ECMO and VA-ECMO use when it is published. ${ }^{29}$ For now, it seems reasonable to reserve VA-ECMO for highly selected cases of COVID-19 in refractory CS with echocardiographic evidence of reduced biventricular function, where there is a perceived reasonable probability of benefit as a BTR. Discussions around provision of therapy should be made on a case-bycase basis as part of an advanced CS team that involves input from cardiac surgery, cardiology, intensivists, and advanced heart failure/transplant physicians to guide appropriate use of this potentially life-saving therapy.

\section{Funding Sources}

There were no funding sources. 


\section{Disclosures}

The authors have no conflicts of interest to disclose.

\section{References}

1. Rodriguez-Morales AJ, Cardona-Ospina JA, Gutiérrez-Ocampo E, et al. Clinical, laboratory and imaging features of COVID-19: a systematic review and meta-analysis. Travel Med Infect Dis 2020 Mar 13 [Epub ahead of print].

2. Paterlini M. On the front lines of coronavirus: the Italian response to covid-19. BMJ 2020;368:m1065.

3. Grasselli G, Pesenti A, Cecconi M. Critical care utilization for the COVID-19 outbreak in Lombardy, Italy. JAMA 2020 Mar 13 [Epub ahead of print].

4. Keebler ME, Haddad EV, Choi CW, et al. Venoarterial extracorporeal membrane oxygenation in cardiogenic shock. JACC Heart Fail 2018;6: 503-16.

5. Li M, Gu S-C, Wu X-J, et al. Extracorporeal membrane oxygenation support in 2019 novel coronavirus disease. Chin Med J (Engl) 2020 Feb 28 [Epub ahead of print].

6. Li X, Guo Z, Li B, et al. Extracorporeal membrane oxygenation for coronavirus disease 2019 in Shanghai, China. ASAIO J 2020 Mar 30 [Epub ahead of print].

7. World Health Organization. Clinical management of severe acute respiratory infection (SARI) when COVID-19 disease is suspected: interim guidance [Internet]. Available at: https://apps.who.int/iris/rest/ bitstreams/1272156/retrieve. Accessed March 13, 2020.

8. Alhazzani W, Møller MH, Arabi YM, et al. Surviving sepsis campaign: guidelines on the management of critically ill adults with Coronavirus Disease 2019 (COVID-19). Crit Care Med 2020 Mar 27 [Epub ahead of print].

9. Zhou F, Yu T, Du R, et al. Clinical course and risk factors for mortality of adult inpatients with COVID-19 in Wuhan, China: a retrospective cohort study. Lancet 2020;395:1054-62.

10. Yang X, Yu Y, Xu J, et al. Clinical course and outcomes of critically ill patients with SARS-CoV-2 pneumonia in Wuhan, China: a singlecentered, retrospective, observational study. Lancet Respir Med 2020 Feb 24 [Epub ahead of print].

11. Xiong T-Y, Redwood S, Prendergast B, Chen M. Coronaviruses and the cardiovascular system: acute and long-term implications. Eur Heart J 2020 Mar 18 [Epub ahead of print].

12. Driggin E, Madhavan MV, Bikdeli B, et al. Cardiovascular considerations for patients, health care workers, and health systems during the Coronavirus Disease 2019 (COVID-19) pandemic. J Am Coll Cardiol 2020 Mar 18 [Epub ahead of print].

13. Madjid M, Safavi-Naeini P, Solomon SD, Vardeny O. Potential effects of coronaviruses on the cardiovascular system. JAMA Cardiol 2020 Mar 27 [Epub ahead of print].

14. Wang D, Hu B, Hu C, et al. Clinical characteristics of 138 hospitalized patients with 2019 novel coronavirus-infected pneumonia in Wuhan, China. JAMA 2020;323:1061-9.

15. Arentz M, Yim E, Klaff L, et al. Characteristics and outcomes of 21 critically ill patients with COVID-19 in Washington State. JAMA 2020 Mar 19 [Epub ahead of print].
16. Inciardi RM, Lupi L, Zaccone G, et al. Cardiac involvement in a patient with Coronavirus Disease 2019 (COVID-19). JAMA Cardiol 2020 Mar 27 [Epub ahead of print].

17. Shi S, Qin M, Shen B, et al. Association of cardiac injury with mortality in hospitalized patients with COVID-19 in Wuhan, China. JAMA Cardiol 2020 Mar 25 [Epub ahead of print].

18. Guo T, Fan Y, Chen M, et al. Cardiovascular implications of fatal outcomes of patients with Coronavirus Disease 2019 (COVID-19). JAMA Cardiol 2020 Mar 27 [Epub ahead of print].

19. Hu H, Ma F, Wei X, Fang Y. Coronavirus fulminant myocarditis saved with glucocorticoid and human immunoglobulin. Eur Heart J 2020 Mar 16 [Epub ahead of print].

20. Zeng JH, Liu Y-X, Yuan J, et al. First case of COVID-19 infection with fulminant myocarditis complication: case report and insights. Preprints 2020 Mar 11 [Epub ahead of print].

21. Extracorporeal Life Support Organization. Extracorporeal Life Support Organization (ELSO) Guidelines for Adult Cardiac Failure [Internet]. Available at: https://www.elso.org/Portals/0/IGD/Archive/FileManager/ e76ef78eabcusersshyerdocumentselsoguidelinesforadultcardiacfailure1.3. pdf. Accessed March 20, 2020.

22. Schmidt M, Burrell A, Roberts L, et al. Predicting survival after ECMO for refractory cardiogenic shock: the survival after veno-arterial-ECMO (SAVE)-score. Eur Heart J 2015;36:2246-56.

23. Ogino M, Paden M, McMullan M, et al. ELSO guidance document: ECMO for COVID-19 patients with severe cardiopulmonary failure [Internet]. Available at: https://www.elso.org/Portals/0/Files/pdf/ECMO for COVID 19 Guidance Document.Final 03.24.2020.pdf. Accessed March 20, 2020.

24. Arora R, Krahn A, Lamarche Y, Légaré J-F, Ruel M. Urgent communication from the CCS/CSCS/CANCARE Society Covid-19 ECMO Coordinated Response Team [Internet]. Available at: https://ccs.ca/ images/Images_2020/ECMO_Coord_Resp_Team_CCS_CSCS_CANC ARE_17Mar2020.pdf. Accessed March 20, 2020.

25. Ramanathan K, Antognini D, Combes A, et al. Planning and provision of ECMO services for severe ARDS during the COVID-19 pandemic and other outbreaks of emerging infectious diseases. Lancet Respir Med 2020 Mar 20 [Epub ahead of print].

26. MacLaren G, Fisher D, Brodie D. Preparing for the most critically ill patients with COVID-19. JAMA 2020 Feb 19 [Epub ahead of print].

27. Emanuel EJ, Persad G, Upshur R, et al. Fair allocation of scarce medical resources in the time of Covid-19. N Engl J Med 2020 Mar 23 [Epub ahead of print].

28. Thomas S, Stevenson D, Otu AA, et al. Microbial contamination of heater cooler units used in extracorporeal membrane oxygenation is not aerosolized into the environment: a single-center experience. Infect Control Hosp Epidemiol 2020;41:242-4.

29. Bassi GL, Suen J, Fraser J. Extracorporeal membrane oxygenation for 2019 novel coronavirus acute respiratory disease (ECMOCARD) Study [Internet]. Available at: https://www.elso.org/Portals/0/Files/ ECMOCard/2019nCOv ECMO 03.17.20.pdf. Accessed March 20, 2020. 